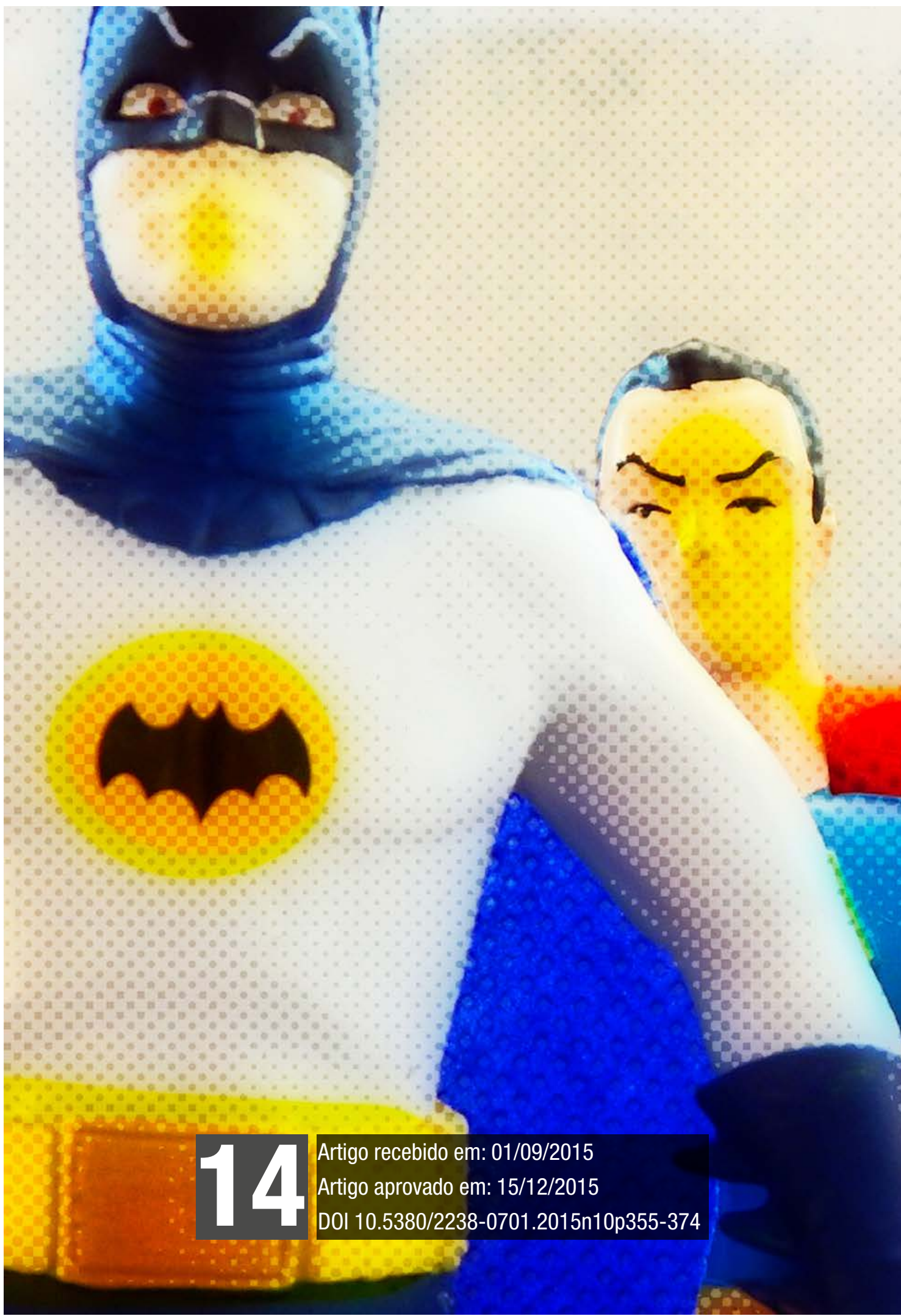


AÇÃO MIDIÁTICA, n. 10. Jul/Dez. 2015. Curitiba. PPGCOM-UFPR. ISSN 2238-0701 


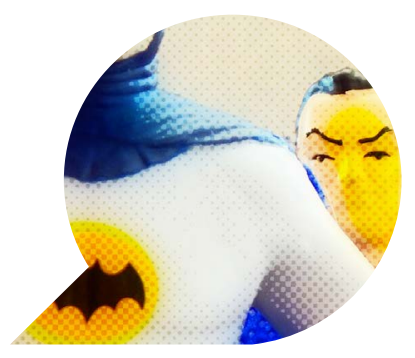

\title{
Batman versus Super-homem: uma metáfora dos quadrinhos para o estudo do jornalismo multimídia
}

\author{
Batman versus Superman: a metaphor from \\ the comics to the study of multimedia journalism
}

Batman versus Superman: una metáfora de los cómics para el estudio del periodismo multimedia

\section{ALEXANDRE LENZI *}

Resumo: Por meio de levantamento bibliográfico, de entrevistas com profissionais do UOL TAB, nova seção multimídia do portal UOL e da análise de conteúdo das 30 primeiras edições da referida publicação, este artigo apresenta um estudo sobre a prática do jornalismo multimídia, em que um mesmo profissional produz material em diferentes formatos. Para reflexão sobre o tema, propõe-se uma metáfora baseada no universo dos quadrinhos da DC Comics: no papel do Super-homem, apontamos o profissional desejado por empresários e gestores de comunicação, um superjornalista que produza sozinho para diferentes plataformas com a mesma competência; enquanto a imagem do Batman é associada ao profissional que faz parte de equipes integradas e polivalentes, onde treinamento e parcerias são palavras de ordem.

\footnotetext{
* Doutorando em Jornalismo (UFSC). Mestre em Jornalismo (UFSC). E-mail: lenzi.alexandre@gmail.com
} 
Palavras-chave: Jornalismo multimídia; Rotina de produção; Convergência.

Abstract: Based on bibliographical research, interviews with UOL TAB professionals - a multimedia section of website UOL -, and on the analysis of the 30 first editions of UOL TAB, this article presents a study about the practice of multimedia journalism, which requires professionals capable of creating contents for different platforms. With intent to debate this subject, it is proposed a metaphor that arises in the DC Comics' universe: assuming Superman's position, we point out the professional that businessmen and managers from the communication field look for, a superjournalist that is able to produce, all by himself, contents for different platforms with the same proficiency. On the other hand, the Batman figure is associated with a professional that is part of integrated teams, guided by training and partnership.

Keywords: Multimedia journalism; Routine production; Convergence.

Resumen: A partir de la investigación bibliográfica, del entrevistas con profesionales del UOL TAB, nueva sección multimedia del portal UOL, y del análisis de las primeras 30 ediciones de esta publicación, este artículo presenta un estudio sobre el ejercicio del periodismo multimedia, donde el mismo profesional produce contenido en diferentes formatos. Para la reflexión sobre el tema, proponemos una metáfora basada en el universo de DC Comics: en papel del Superman, apuntamos el profesional del agrado de los gerentes de las empresas del comunicación, uno super-periodista que produce para distintas plataformas con la misma competencia; mientras que la imagen del Batman asociamos con el profesional de los equipos integradas e polivalentes, donde predominan entrenamiento $e$ colaboraciones.

Palabras clave: Periodismo multimedia; Rutina de Producción; Convergencia. 


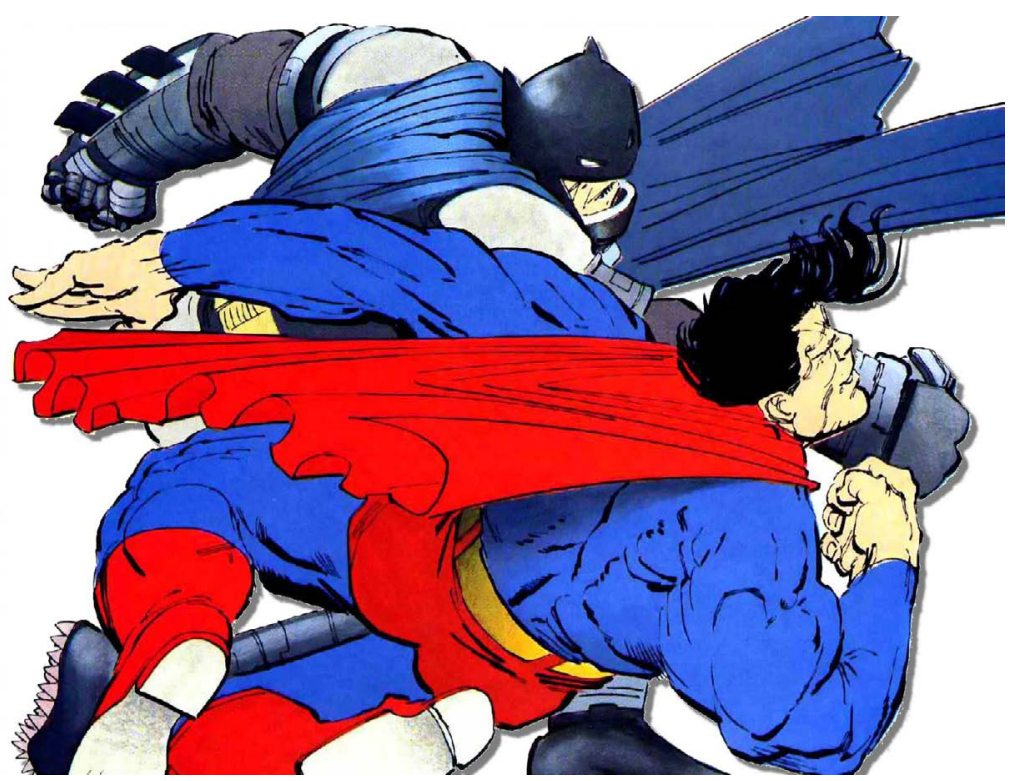

Figura 1: Imagem da história em quadrinhos O Cavaleiro das Trevas, de Frank Miller (DC Comics/Reprodução).

\section{Introdução}

De um lado, o último ser da espécie, um alienígena que tem forma humana e superpoderes incomparáveis que o capacitam para enfrentar sozinho qualquer desafio. Do outro, um ser humano treinado desde criança para ser super qualificado em determinadas áreas e que lidera uma equipe fortemente capacitada em missões que pessoas comuns dificilmente cumpririam. Super-homem e Batman ${ }^{1}$, respectivamente, são personagens criados pela norte-americana $D C$ Comics, na década de 1930. A proposta deste artigo é trazer os exemplos fantasiosos para o debate sobre um problema real que preocupa profissionais da comunicação mundo afora: a figura do jornalista multitarefa. O trabalho abrange levantamento bibliográfico sobre a prática do jornalismo multimídia no cenário das redações convergentes e o impacto das novas tecnologias nas relações de trabalho, acompanhado por entrevistas realizadas pelo autor com profissionais do UOL TAB, nova seção multimídia do portal UOL, e pela análise de conteúdo das 30 primeiras edições da referida seção ${ }^{2}$, publicadas entre outubro de 2014 e maio de 2015. 
Parte-se de um levantamento bibliográfico sobre o atual cenário da convergência das redações, acompanhado por uma descrição dos perfis dos dois personagens do universo dos quadrinhos, em busca da construção de uma metáfora que chame a atenção para as novas demandas exigidas dos profissionais do jornalismo. Para ilustração prática do debate, optou-se como exemplo a produção dos especiais multimídia do UOL TAB. Foram analisadas as 30 primeiras edições, buscando identificar os diferentes elementos utilizados ao longo das reportagens, e entrevistados um editor e três repórteres, levantando informações sobre o perfil da equipe envolvida e sobre a rotina de produção dos primeiros especiais. As entrevistas foram realizadas por e-mail entre outubro e novembro de 2014. Foram selecionados o editor e os três repórteres que fazem parte do UOL TAB desde o início.

\section{O cenário da convergência}

Hoje, com redações convergentes - aquelas onde os mesmos profissionais abastecem diferentes plataformas, como jornais impressos, sites de notícias e até emissoras de rádio e canais de televisão - o trabalho do jornalista foi ampliado. Um único profissional, além das funções de apurar e escrever, pode - ou deve, dependendo da exigência do contratante - fotografar e filmar, mesmo que apenas com o celular, captar áudios, abastecer a redação com novos fragmentos de informação para uma cobertura em tempo real e levantar detalhes para infográficos e para uma edição mais aprofundada da história a ser publicada na edição impressa do dia seguinte. Imaginar alguém que daria conta de tudo isso, garantindo qualidade do material em todas as suas versões, é o mesmo que acreditar em um Super-homem de verdade. Exigir isso dos novos profissionais, com o rótulo de "polivalência" ou de "multimídia", é exigir não um jornalista, mais sim um superjornalista.

É importante afirmar aqui que não temos a pretensão de que as redações jornalísticas ainda reservem espaço em seus quadros profissionais para aqueles repórteres exclusivos de texto. Mas é preciso reconhecer a dificuldade em garantir que cada jornalista seja especialista em todas as áreas, abastecendo diferentes plataformas com trabalho de padronizada qualidade. No caso de um jornalista espe- 
cializado em texto, ele deve estar minimamente preparado para, em situações especiais, fazer mais do que sua rotina: gravar um vídeo ou entrar ao vivo para um boletim de rádio de uma emissora do mesmo grupo. Mas transformar isso em rotina pode colocar em risco a qualidade técnica do material final - se não em todas, em pelo menos algumas das mídias - e o que é mais grave, a qualidade da apuração das informações. Se é preciso gravar ou anotar, filmar, fotografar, atualizar site em uma mesma jornada, é real a chance de reduzir o tempo dedicado ao trabalho de checagem.

A ideia de recorrer à comparação ao fantasioso Super-homem surge no sentido de, justamente, chamar a atenção para o quão complexa é a proposta de um jornalista multitarefa responsável pela produção de qualidade para diferentes plataformas. Com esse discurso, pretendemos reforçar alertas de pesquisadores como Mick (2015), Figaro (2013), Negredo e Salaverría (2009), Sant'Anna (2008), Avilés (2006), entre outros. Em recente mapeamento de novas funções e atividades do trabalho jornalístico no cenário de convergência digital, Jacques Mick (2015) confirma que o acréscimo de novas atividades intensifica a exigência dos empregadores quanto a profissionais "multitarefa"; e nas mudanças em relação aos processos de produção, diante da redução de receitas e da fragilização do modelo de negócios das empresas jornalísticas, destacam-se, além da imposição da multifuncionalidade, a precariedade dos vínculos de contratação e a juvenilização da categoria.

É preciso lembrar que o que exige muita competência para ser feito em um único meio - impresso, televisivo, radiofônico ou digital - torna-se ainda mais difícil quando se exige do jornalista atuação em mais de uma frente. Sant'Anna (2008) defende que a sobrecarga de tarefas e de preocupações com aspectos técnicos, por mais simplificadas que sejam as operações dos novos aparelhos digitais, pode afetar a qualidade na apuração. Diante deste quadro, a alternativa não é desistir de uma produção multimídia, mas investir na formação de um novo perfil de jornalistas, no qual o individualismo e o protagonismo cedem espaço para o trabalho em equipe. "O trabalho de apuração da reportagem, como empreitada solitária, fortemente marcada por talentos pessoais que funcionam como marcas distintivas aliadas ao nome de um profissional, perderia parte de seu papel" (SANT'ANNA, 2008, p. 23). 
Ramón Salaverría e Samuel Negredo (2009) também reforçam esta necessidade de fortalecer o trabalho em equipe nas novas redações. A ideia do jornalista multimídia como um profissional que, aparentemente, pode realizar qualquer tipo de tarefa no contexto da convergência das redações é vista como um mito pelos autores espanhóis. Eles reconhecem que muito tem sido discutido sobre a chegada do jornalista multimídia, como um profissional para todos os fins, supostamente capaz de gerar conteúdo tanto textual quanto audiovisual para mídias diversas. Mas apontam que a realidade mostra-nos que esse perfil está longe de se tornar uma regra e argumentam que a figura profissional do jornalista chamado multitarefa recebe quantidades infinitas de funções jornalísticas, que anteriormente diferentes profissionais realizavam separadamente. Neste contexto, esses profissionais são avaliados mais pelo número de funções que realizam e pela quantidade de conteúdo que geram, do que por suas qualidades jornalísticas. "Este modelo destrói a especialização técnica e gera produtos textuais e audiovisuais que são essencialmente medíocres. Pau para toda obra, mestre em nada" (NEGREDO e SALAVERRÍA, 2009, p. 63, tradução do autor) ${ }^{3}$.

Não aprofundados neste artigo, até mesmo efeitos físicos e psicológicos são resultados que podem surgir com a rotina desgastante comum na profissão do jornalista, acirrada com o novo cenário de convergência. Para citar apenas um estudo na área, Heloani (2003) alerta para o nível elevado de estresse entre jornalistas, o que chega a motivar a troca de profissão após longos períodos de trabalho em redação.

O que se concluiu pelos depoimentos é que a maioria desses sujeitos simplesmente ama seu trabalho, são apaixonados pelo que fazem, fetichizam sua profissão. Apesar do "glamour", do fetiche pelo jornalismo, alguns buscam outras saídas pois, ao contrário de outros colegas, não suportam mais adiar a felicidade e temem não mais aguentarem o ritmo de trabalho por muito tempo, ou melhor, até a aposentadoria (HELOANI, 2003, p. 80).

Trata-se, ainda, de uma preocupação que motiva um debate com o enfoque legal. No Brasil, os trabalhadores dos jornais são contratados ou por meio de contrato formal, regido pela Consolidação das

3 Texto original: "This model destroys technical specialization and generates textual and audiovisual products that are essentially mediocre. Jack of all trades, master of none". 
Leis do Trabalho (CLT); por contratos de pessoa jurídica (terceirização); ou por vínculos mais precários, como os de freelancers. $\mathrm{Na}$ maioria dos contratos dos jornais, a jornada estabelecida é de 44 horas semanais, que é o máximo tolerado pela Constituição de 1988. Mas com as fusões das redações do on-line e do impresso, os jornais diários estão se precavendo contra possíveis ações trabalhistas no futuro referentes a acúmulo de funções, sugere Camila Silva (2011). Grandes empresas estão renovando os contratos de trabalho e inserindo novas cláusulas, que exigem que o mesmo trabalhador produza conteúdo para diversas plataformas (vídeo, áudio, texto e foto) sem a necessidade de pagamento adicional. "É o que está sendo chamado de contrato multimídia, uma forma de regularizar o acúmulo de funções" (SILVA, 2011, p. 161). Adghirni e Pereira (2011) também reconhecem que as exigências de se produzir conteúdo para vários formatos midiáticos exige o desenvolvimento de novas competências e uma sobrecarga de trabalho, que dificilmente é remunerada. E citam a mesma metáfora aqui proposta:

A verdade é que a roupa de Super-Homem não serve mais. O jornalista prefere vestir a fantasia da circunstância, que lhe permite subir na vida profissional ou simplesmente sobreviver diante do desafio das rotinas produtivas infernais às quais está submetido dentro de um mercado desconfigurado pelas tecnologias e pela legislação trabalhista (ADGHIRNI e PEREIRA, 2011, p. 48).

Em ensaio em que busca contestar o que define como mitos sobre a convergência jornalística, José Avilés (2006) afirma que o pano de fundo em muitos mercados é, simplesmente, uma estratégia de redução de custos e que a sinergia muitas vezes não passa de mecanismos encobertos para reduzir pessoal. Estudando a realidade brasileira, Virginia Fonseca (2008) aponta que o atual cenário pode ser enquadrado em uma terceira fase de reestruturação das redações jornalísticas onde a adaptação a um novo contexto econômico redesenha a organização de cargos, com extinção de algumas funções.

A primeira fase foi vivenciada nos anos 1970, em uma transição de um modelo fordista para o pós-fordista, passando de um gerenciamento rígido da "linha de produção" para um sistema onde se manifesta a flexibilidade dos processos. Nesta fase, enquanto ingressavam nas redações os primeiros microcomputadores e seus programas de edição 
de texto e editoração eletrônica, extinguiram-se etapas e funções de setores de apoio, que executavam atividades não jornalísticas, como as de composição, revisão de provas e montagem. A segunda fase é representada pelo acúmulo de funções e consequentemente de redução de cargos e custos na linha de produção, com postos como o de pauteiro, copidesque e o revisor desaparecendo das redações. E em uma terceira fase que se anuncia, as habilidades requeridas são para dar conta de novas competências nas organizações multimídia. $\mathrm{Na}$ mesma linha de autores já citados, Fonseca aponta o risco desse acúmulo de funções se traduzir em jornadas maiores, com o agravante de não ter qualquer repercussão salarial e ainda reduzir novamente o número de vagas.

O padrão multimídia é buscado através da convergência entre tecnologias, e obtido no compartilhamento de conteúdos - entre veículos de comunicação da mesma empresa, entre jornais, entre editorias, entre cadernos, entre seções. Em ambos os casos, o objetivo final é reduzir custos para aumentar lucros (FONSECA, 2008, p. 241).

Em ampla pesquisa sobre as mudanças no mundo do trabalho do jornalista, Roseli Figaro (2013) também alerta para questões como vínculos empregatícios precários, baixos salários, extensas jornadas de trabalho, exigências de atualização constante no uso de ferramentas digitais de prospecção de informações, de apuração e edição. Ao mesmo tempo, afirma que o tratamento da informação aparece como o maior desafio: “o processo de seleção, análise e interpretação exige maturidade intelectual, profundo compromisso com a ética jornalística e com os fundamentos da produção do discurso jornalístico" (FIGARO, 2013, versão $e$-book, sem numeração de páginas). É uma demanda crescente que reforça cada vez mais a imagem do jornalista moderno como o superjornalista multitarefa e multitalentoso, o que nos faz voltar à metáfora do herói com poderes únicos. A associação da figura do jornalista com o personagem do Super-homem é favorecida pela própria ficção: nos quadrinhos, o herói disfarça-se de humano na figura do repórter Clark Kent, informação preservada nas adaptações para desenhos, séries de TV e produções cinematográficas.

A metáfora do Super-homem a partir dos dilemas da profissão de jornalista também foi utilizada por Geraldinho Vieira (1991) ao apresentar o que define como "complexo de Clark Kent", apontando 
que o poder da palavra, da imagem, da seleção e interpretação dos fatos, e de sua multiplicação cria a ilusão do repórter super-homem e que a ficção colore uma profissão onde o dia a dia é uma maravilhosa aventura na procura da verdade. Ao questionar o mito da objetividade jornalística, discussão ainda vigente, mas que não será abordada aqui, o autor afirma:

A ficção não mostrou, entretanto, quanta arrogância adquirem o empresário e o jornalista que uma vez embriagados por toda essa ilusão rompem os mais primários preceitos éticos. [...] Não mostrou que por mais honesto e ético que seja o profissional da mídia ele é tão humano quanto o leitor que também lê com olhos diferentes aquilo que lhe agrada e aquilo que lhe fere (VIEIRA, 1991, p.12).

Para Vieira (1991), detectar o complexo de Clark Kent é estabelecer a discussão sobre a necessidade de uma convivência entre regras técnicas e preceitos éticos no exercício do jornalismo, e estabelecer os limites entre o repórter (Clark Kent) e o indivíduo, que a partir de poderes únicos e privilegiados (o Super-homem), se dá o direito de uma intervenção egocêntrica para transformar a sociedade ou mantê-la nos padrões vigentes em função de seus exclusivos interesses. Acrescentamos as preocupações de que a busca pelo repórter super-homem pode fazer com que empresários e gestores exijam que um único profissional cumpra funções antes realizadas por mais pessoas; e de que jornalistas encarem esse desafio diante do risco de perder os empregos, mesmo que para isso reduzam a qualidade técnica do material final ou até mesmo a intensidade do trabalho de apuração e checagem.

Reflexão que vai ao encontro do alerta da pesquisadora Sylvia Moretzsohn (2002), que apresenta a hipótese de que a velocidade nos jornais é consumida como fetiche, pois "chegar na frente" torna-se mais importante do que "dizer a verdade", trazendo riscos crescentes de imprecisão. Com o agravante de que a estrutura industrial da empresa jornalística está montada para atender essa demanda pela velocidade. Exemplo disso é o perfil apontado pela autora como preferido das empresas para os profissionais dos meios on-line: jovens recém-saídos da universidade, ou mesmo ainda estudantes, pois supostamente não apresentam os "vícios" de "escrever muito" e "querer contextualizar a matéria" que caracterizariam os jornalistas de veículos impressos. Trata-se de uma inversão de valores a ser 
combatida. A qualidade da apuração aprofundada e plural deve, sim, continuar como base do trabalho jornalístico.

Adghirni, Jorge e Pereira (2009) defendem que o jornalista multimídia será o jornalista capaz de trabalhar com mais de uma mídia e, sobretudo, aquele que tem poderes para pensar qual será a melhor mídia para veicular a mensagem que ele processou e hierarquizou para melhor mostrar a quem o lê, assiste ou ouve. E embora o mercado exija a capacidade de realizar diferentes tarefas, qualificações como um bom texto e faro pela notícia não podem ficar em segundo plano. Pelo contrário, apontam que a pressão do tempo aumentou a gama de responsabilidades.

Dentro desse contexto, treinamento e trabalho em equipe são dois pontos que precisam ser valorizados pelos empresários e gestores de empresas de comunicação e desenvolvidos pelos profissionais. São dois pontos, também, que nos fazem voltar ao universo dos quadrinhos, agora para o personagem também conhecido como HomemMorcego. Batman é o alter ego de Bruce Wayne, que quando criança testemunhou o assassinato de seus pais em um assalto. De família bilionária, o jovem buscou superar o trauma viajando pelo mundo para tentar entender a mente criminosa e estudar diferentes tipos de artes marciais e técnicas de combate, promovendo sua qualificação física e intelectual. Adulto, passou a combater criminosos usando um uniforme inspirado na figura do morcego, que o amedrontava quando criança, e utilizando armas brancas (ver seus pais mortos com tiros de revólver o fez evitar armas de fogo). Diferentemente de outros super-heróis, Batman não tem qualquer poder sobre-humano, usando apenas o intelecto, habilidades investigatórias, tecnologia e um físico bem preparado no combate ao crime. Outra habilidade do personagem é a capacidade de liderança. Para fazer referência a apenas alguns personagens, ele tem dois parceiros diretos em ações de combate ao crime, Robin e Batgirl, além do suporte indireto do comissário de polícia James Gordan e do mordomo Alfred Pennyworth.

Se a metáfora do Super-homem nos faz refletir o quanto irreal nos parece a figura do jornalista multitarefa capacitado para produzir sozinho com qualidade para diferentes plataformas, o universo também fantasioso do Batman dialoga com nossa proposta de reflexão ao buscar trazer indícios de realidade para as suas histórias: o 
personagem principal é, em sua essência, um ser humano. $\mathrm{O}$ que o diferencia de tantos outros super-heróis é que ele não tem superpoderes, não veio de outro planeta nem foi picado por insetos radiativos ou passou por experimentos científicos mirabolantes. É “apenas" resultado de um trabalho de treinamento intenso em busca da máxima qualificação possível. E mesmo assim, precisa liderar uma equipe igualmente treinada para atingir os seus objetivos. E é essa mensagem que queremos resgatar dessa metáfora.

O novo jornalista (novo pelo perfil exigido, e não necessariamente pela idade) precisa de treinamento intenso para produzir conteúdos com qualidade informativa em diferentes plataformas com um padrão de qualidade técnica. E vai precisar cada vez mais trabalhar em equipe desde o início do processo.

Voltamos a citar Negredo e Salaverría (2009), para quem a convergência das redações não pode ser apenas uma maquiagem digital para perpetuar o velho jornalismo e nem uma desculpa para as redações trabalharem com menos gente. Pelo contrário, os autores sugerem o investimento em treinamento do pessoal para lidar com as diferentes ferramentas que passam a ser incorporadas à rotina. $\mathrm{E}$ treinamento exige inovações técnicas e mudanças de mentalidade.

Denunciando a falta de investimento por parte das empresas em treinamento, Marcelo Kischinhevsky (2009) lembra que, no Brasil, entre os críticos, a "multi-habilidade" já ganhou o nome de "multifunção". Cada vez mais, alerta o autor, os jornalistas com conhecimentos prévios de softwares de edição de áudio e vídeo e/ou programação para web são priorizados em processos seletivos, por dispensarem gastos em treinamento. Acrescenta que são escassas as evidências de que o consumidor de conteúdos jornalísticos venha a ser beneficiado pela convergência.

Os cortes de custos decorrentes da integração de redações só acirram a concentração na grande imprensa, reduzindo a pluralidade de vozes que condiciona o pleno acesso à informação. Ter uma imprensa independente e plural é ponto de partida para a construção e a consolidação da democracia no mundo contemporâneo. E não há jornalismo livre sem jornalistas bem preparados e remunerados, a salvo de pressões econômicas e políticas de toda ordem. A convergência nas redações só poderá prosperar quando se forjar 
uma nova cultura profissional, em que o trabalho colaborativo seja uma construção coletiva, e não uma imposição do departamento financeiro (KISCHINHEVSKY, 2009, p.71).

Kischinhevsky (2009) sugere que a nova lógica produtiva deverá ser acompanhada de um arcabouço regulatório relativo ao exercício da profissão de jornalista, estabelecendo critérios claros para uma digna remuneração correspondente à atividade multimídia e também punições para eventuais abusos; além de ser necessário rever as grades curriculares dos cursos de Jornalismo. Um longo caminho a ser percorrido, o que reforça a importância desse reflexão para que diferentes veículos e instituições de ensino deem os primeiros passos nesse sentido.

\section{A experiência do UOL TAB: multimídia, mas com trabalho em equipe}

A partir do levantamento bibliográfico, buscamos também um exemplo do atual cenário da prática da reportagem multimídia para ilustrar o debate. Optou-se pela seção UOL TAB, lançado pelo UOL em outubro de 2014. A escolha deve-se ao fato de, além de propor uma linguagem diferenciada, a seção lança o desafio de incorporar a prática da reportagem multimídia na rotina de uma redação brasileira, diante da oferta de uma nova edição toda semana, sempre às segundas-feiras.

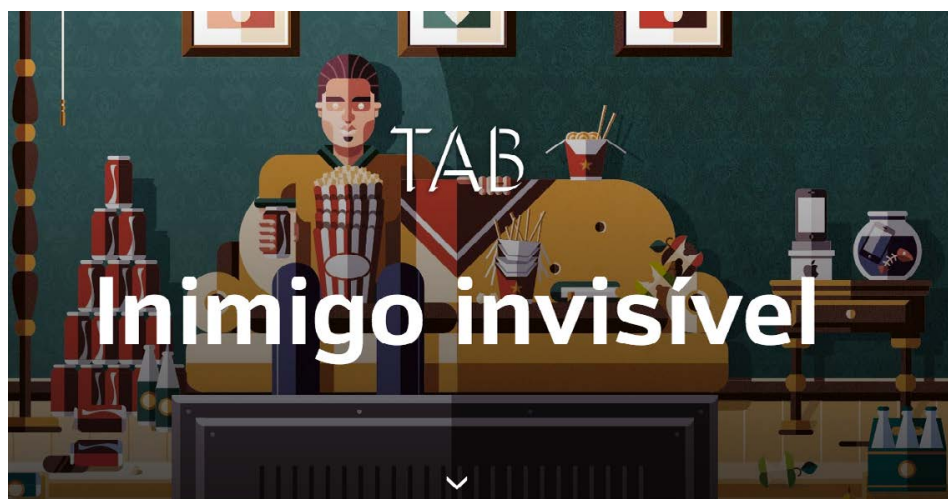

Figura 2: Página inicial da edição do UOL TAB sobre reciclagem de lixo (UOL TAB/Reprodução). 
Para contextualizar, é preciso reconhecer, no entanto, que no Brasil o jornal Folha de S. Paulo largou na frente e, em dezembro de 2013, inovou com a série Tudo Sobre, que já contava com cinco publicações quando este texto foi produzido 4 . A produção é marcada por textos longos, fotos abertas, áudios, infográficos animados e até games, como os aplicativos que possibilitam ao internauta "pilotar" um helicóptero sobre a obra tema da primeira reportagem (no caso, a usina hidrelétrica de Belo Monte, em construção no Pará).

Em nossa análise do UOL TAB, selecionamos as 30 primeiras edições e realizamos entrevistas por e-mail com um editor e três repórteres. A tendência mais evidente que se percebe no material é a proposta de consolidar a passagem do trabalho de justaposição, onde peças de diferentes mídias são diagramadas em conjunto em uma mesma seção on-line, mas sem necessariamente estarem realmente integradas, para uma experiência de imersão proporcionada por peças que se complementam em uma nova unidade multimídia.

A análise da linguagem utilizada pela nova seção é aprofundada em outro trabalho (LENZI, 2015), estando nosso foco aqui no processo produtivo da nova seção. No entanto, a partir da análise de conteúdo realizada, é importante afirmar que, tomando como referência as 30 primeiras edições do UOL TAB, encontramos matérias que integram textos longos - com média aproximada de 1.700 palavras ou 10.000 caracteres com espaços em cada edição -, fotos usadas como ilustração e telas de fundo, infográficos, vídeos e enquetes. Aparecem também entrevistas exibidas em arquivos de áudio e recursos de sons utilizados como trilhas para infográficos. Em todas as edições, o texto aparece como elemento principal, fio condutor para as demais peças. Mas os demais elementos, mesmo que não protagonistas, têm papel representativo na narrativa. As fotos são trabalhadas em composição com todo o material restante, ora como imagem destacada, ora como tela de fundo para outros conteúdos. Outro recurso comum, os infográficos desempenham principalmente um papel didático, destrinchando conceitos e trazendo curiosidades. Já os vídeos são utilizados para "humanizar" as matérias, com apresentação de relatos de personagens que ilustram o tema. Ou ainda como alternativa para trazer opiniões de especialistas.

4Especiais TudoSobre. Publicados entre dezembro de 2013 eagosto de 2015. Disponíveis em: <http://www1.folha.uol.com.br/tudosobre/>. Acesso em: ago. de 2015. 

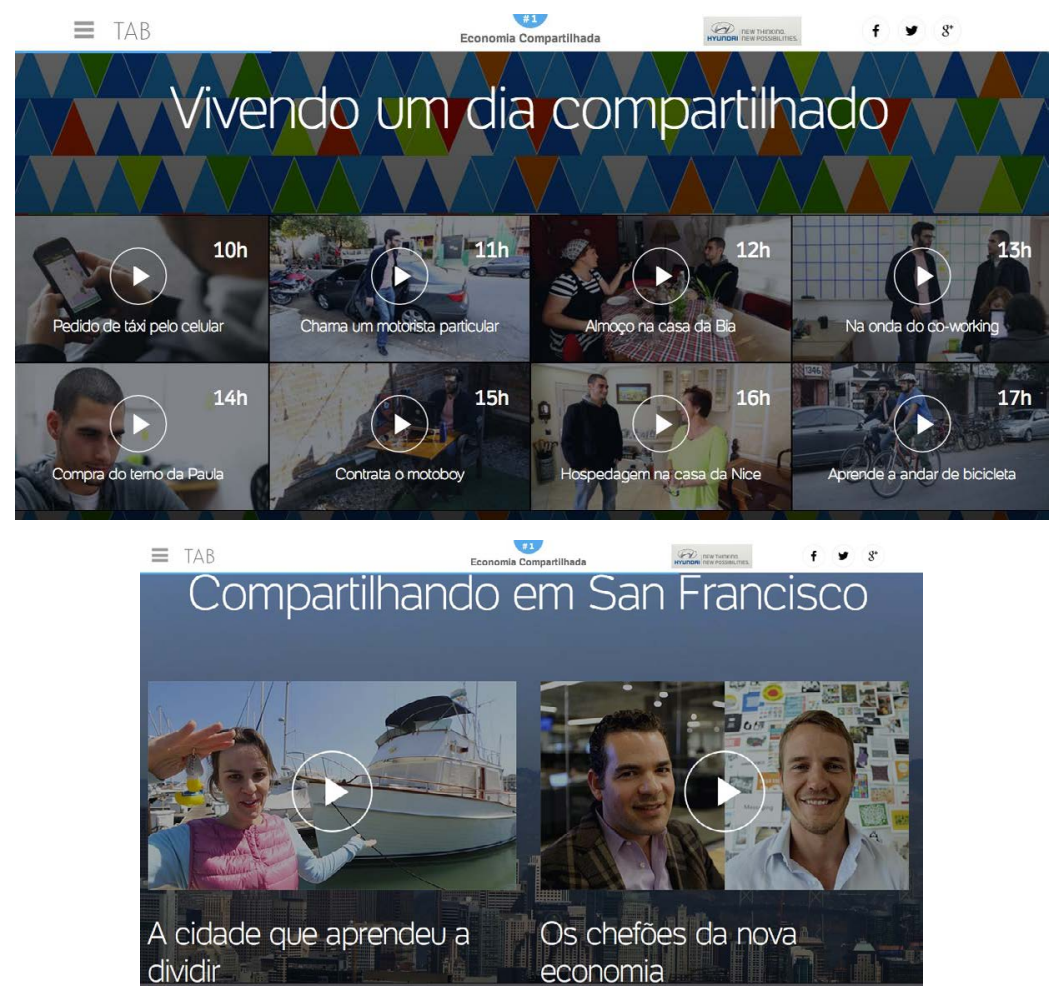

Figuras 3 e 4: Seções com vídeos da primeira edição do UOL TAB, que abordou o tema economia compartilhada (UOL TAB/Reprodução).

Voltemos o nosso olhar sobre o processo de produção: para lançar o UOL TAB foi mobilizada uma equipe de 20 pessoas, sendo 12 exclusivas e as oito demais conciliando a participação na nova seção com o trabalho em outras áreas do portal. A equipe começou a ser estruturada cerca de 40 dias antes do lançamento da primeira edição. Não houve um treinamento específico para a execução do novo projeto. Mas, segundo a empresa, todos os jornalistas envolvidos são profissionais com ao menos 10 anos de experiência na área cada um. A falta de treinamento reforça os alertas de pesquisadores aqui já citados, problema amenizado apenas pelo fato de no próprio quadro funcional da empresa - no caso um portal de jornalismo que já nasceu on-line - existirem profissionais com longa experiência em produção multimídia.

O que diferencia a nova seção do já experimentado até então, 
segundo o editor Daniel Tozzi ${ }^{5}$, está na tentativa de "colocar a experiência de consumir a informação como parte da informação em si". Tozzi valoriza o perfil da equipe: "Cada um tem uma especialidade, mas são versáteis para circularem pelos mais diferentes temas, além de terem grande capacidade de realização. O mesmo se aplica aos editores de vídeo, fotografia, design e arquitetura de informação". Para escolha do tema de cada edição, os critérios são bem amplos, mas uma premissa é de que o tema deva conter alguma "novidade real" para o internauta do UOL e que possa despertar alguma ação em quem consumir o TAB. Temas ligados à inovação, comportamento e estilo de vida são os mais frequentes. Nas entrevistas com os repórteres Juliana Carpanez Santiago, Lilian Ferreira e Paulo Terron $^{6}$, destaque para o discurso afinado em valorização do trabalho em equipe, mostrando sintonia com o discurso de autores aqui citados. E, principalmente, dialogando com nossa metáfora dos quadrinhos.

Os três repórteres afirmam que jornalistas, designers, câmeras/ editores de vídeo e webmaster participam de toda a concepção de cada reportagem. O tempo de produção de cada edição varia bastante. Para a primeira, por exemplo, duas repórteres foram diretamente envolvidas - uma ficou duas semanas trabalhando exclusivamente na matéria e outra ficou três semanas, período que incluiu uma viagem internacional. Porém, paralelamente à execução das pautas seguintes, as duas jornalistas participaram de ajustes na primeira edição até a véspera da publicação, totalizando sete semanas de produção. Esse reconhecimento da importância do trabalho em equipe é peça-chave para que o produto final seja não apenas uma peça multimídia de reconhecida qualidade técnica, mas também um produto jornalístico onde foram valorizadas suas características-base, como a confiabilidade das informações apuradas.

Seja em uma tradicional matéria impressa ou em um conteúdo multimídia, o fundamental é que o jornalismo mantenha um debate contextualizado com o cenário atual, relevante para seus leitores e com foco na credibilidade. O UOL tem ao seu favor a estrutura de uma empresa de grande porte e um público já consolidado - segundo dados do próprio portal, na época do lançamento do UOL TAB,

5 Entrevistas por e-mail realizadas pelo autor entre outubro e novembro de 2014 . 6 Entrevistas por e-mail realizadas pelo autor entre outubro e novembro de 2014. 
cada segunda-feira, dia de maior audiência, cerca de 4,5 milhões de internautas visitam a página do portal pelo computador e mais 1,5 milhão de internautas via smartphone.

E tem o suporte de grandes anunciantes também. Ao final de cada edição do UOL TAB, o internauta tem acesso aos links para edições anteriores e, no mesmo espaço, a seção é auto-definida como "uma experiência única e interativa com conteúdo de alta qualidade, em formatos inovadores e com total independência editorial". Em seguida, aparece o texto afirmando que a seção "só é possível por causa do patrocínio de algumas marcas, que também acreditam em conteúdo de qualidade" e uma bem-humorada declaração de amor aos anunciantes. Esse é outro ponto que diferencia a nova seção. $\mathrm{O}$ editor Daniel Tozzi defende que "a qualidade do TAB acolhe bem o anunciante que está disposto a associar sua marca a um conteúdo realmente diferente, ao mesmo tempo no qual isso não ocorre de maneira invasiva”. E afirma que há total independência editorial. Experiência recente, o UOL TAB merece estudos mais profundos. Mas não deixa de ser uma boa referência de trabalho multimídia em equipe que pode ser replicada em grandes portais on-line de notícias.

\section{Considerações finais}

As novas tecnologias que mudam a rotina dos jornalistas não são inimigas. Pelo contrário, agregam e muito ao trabalho jornalístico, como podemos perceber nas edições do UOL TAB aqui analisadas. É importante e necessário buscar aprimorar a linguagem jornalística diante das potencialidades da internet. E é preciso rever estratégias em busca de audiência e lucratividade.

Diante de tantos desafios, o alerta que buscamos reforçar é que a lógica de produção também muda. E é quando se transforma a busca por um novo modelo no mantra "fazer mais com menos", que o sinal vermelho acende. Não dá para fazer o que já se fazia até então, adotar novos recursos, novos produtos e novos ritmos sem investimento em pessoal e em treinamento. O superjornalista multimídia como um único profissional que faz tudo - e faz tudo bem feito - é ficção. É o Super-homem.

O que existe é trabalho em equipe com grupos cada vez mais polivalentes e integrados, dispostos a contribuírem com distintas 
frentes de trabalho. No caso do UOL TAB, o ponto positivo é identificar esse discurso entre os profissionais responsáveis pela nova seção multimídia. O ponto negativo é perceber que empresas do porte do UOL ainda não investem por conta própria no treinamento da equipe. Uma resistência que atrasa os avanços necessários.

O mercado precisa parar de procurar Super-homens, excelentes profissionais prontos e com todos os "poderes" necessários para enfrentar qualquer desafio e deve ficar mais atento para profissionais com o perfil de Batman, com atributos como disposição e dedicação para novos e constantes treinamentos e vocação para trabalhar em equipe, demandas em alta no atual contexto da convergência.

\section{Referências}

ADGHIRNI, Zélia L.; JORGE, Thaïs de M.; e PEREIRA, Fábio H. Jornalismo na internet: desafios e perspectivas no trinômio formação/ universidade/mercado. In: RODRIGUES, Carla (org.). Jornalismo on-line: modos de fazer. Rio de Janeiro: Ed. PUC-Rio; Editora Sulina, 2009. P 75-96.

ADGHIRNI, Zélia L.; PEREIRA, Fábio H. O jornalismo em tempo de mudanças estruturais. Intexto, Porto Alegre: UFRGS, volume 1, número 24, 2011. P 38-57.

AVILÉS, José A. G. Desmitificando la convergencia periodística. Revista Latinoamericana de Comunicación Chasqui, Quito (Equador), n. 94, 2006. P 34-39.

FIGARO, Roseli. As mudanças no mundo do trabalho do jornalista. São Paulo: Atlas, 2013.

FONSECA, Virginia P. da Silveira. Indústria de notícias: capitalismo e novas tecnologias no jornalismo contemporâneo. Porto Alegre: UFRGS, 2008.

HELOANI, José R. M.. Mudanças no mundo do trabalho e impactos na qualidade de vida do jornalista. Relatório de Pesquisa de PósDoutorado - ECA-USP, 2003. 
KISCHINHEVSKY, Marcelo. Convergência nas redações: mapeando os impactos do novo cenário midiático sobre o fazer jornalístico. In: RODRIGES, Carla (org.). Jornalismo on-line: modos de fazer. Rio de Janeiro: Ed. PUC-Rio; Editora Sulina, 2009. P 57-74.

LENZI, Alexandre. Já temos uma alternativa para a reportagem multimídia? In: CHRISTOFOLETTI, Rogério (org). Questões para um jornalismo em crise. Florianópolis: Insular, 2015. P 85-99.

MICK, Jacques. Trabalho jornalístico e convergência digital no Brasil: um mapeamento de novas funções e atividades. In: $1^{\circ}$ Congresso da Associação Internacional de Ciências Sociais e Humanas em Língua Portuguesa (Anais...). Lisboa: 2015. P 6079-6089.

MORETZSOHN, Sylvia. Jornalismo em tempo real: o fetiche da velocidade. Rio de Janeiro: Revan, 2002.

NEGREDO, Samuel; SALAVERRÍA, Ramón. Integrated journalism: Media convergence and newsroom organization. Barcelona: Editorial Sol 90, 2009.

SANT'ANNA, Lourival. O destino do jornal: a Folha de S. Paulo, O Globo e O Estado na sociedade da informação. Rio de Janeiro: Record, 2008 .

SILVA, Camila Rodrigues. Operário multimídia: mudanças do mundo do trabalho nos jornais diários brasileiros. Florianópolis, 2011. Dissertação (Mestrado em Economia). UFSC, 2011.

VIEIRA, Geraldinho. Complexo de Clark Kent: são super-homens os jornalistas. São Paulo: Summus, 1991. 